\title{
La crítica secular en la enseñanza de la literatura: un puente para conectar las letras con las experiencias humanas, las realidades sociales y las instituciones de poder
}

\section{Secular Criticism in the Teaching of Literature: A Bridge to Connect the Letters with Human Experiences, Social Realities and Institutions of Power}

\author{
Esteban Barboza Núñez ${ }^{1}$ \\ Sede de Guanacaste de la Universidad de Costa Rica \\ San José, Costa Rica \\ ebarbo@chorotega.una.ac.cr
}

Recibido 05 de mayo de $2010 \bullet$ Aceptado 24 de junio de 2010

\begin{abstract}
Resumen. Con base en el aporte del crítico literario y pensador palestino Said (1983), quien acuña el término "crítica secular," este artículo analiza la posibilidad de aplicar dicho concepto a la enseñanza de la literatura, tanto en niveles de educación primaria y secundaria, como en niveles superiores. Por crítica secular se debe entender el modo de análisis textual que ve a la literatura inherentemente ligada a las experiencias humanas, a las realidades sociales de los contextos en que es producida y a las instituciones de poder que la propician o la reprimen. La principal propuesta será, entonces, el plantear una metodología para abordar, en el salón de clase, los textos literarios desde una perspectiva mundana; es decir, ligándolos al mundo exterior, al que está fuera de las aulas. En este sentido, y utilizando tanto ejemplos textuales primarios como teoría literaria, el artículo propondrá convertir el estudio de la literatura en una herramienta de análisis, cuestionamiento, desafío y cambio de las realidades que la producen.
\end{abstract}

Palabras clave. Crítica literaria, crítica secular, enseñanza y aprendizaje de la literatura

Abstract. Based on the contribution of Palestinian literary critic and thinker Said (1983), who coined the term "secular criticism," this article analyzes the possibility of applying this concept to the process of teaching literature at elementary, secondary and college levels. We should understand secular criticism as the mode of textual analysis that sees literature inherently linked to human experiences, social realities in which it is produced and to the institutions of power that consent or suppress it. The main proposal of the article will be to suggest a methodology to approach literary texts in the classroom from a mundane perspective; that is, linking them to the outside world. In this sense, and using primary literary sources as examples, as well as literary theory, the article will propose turning the study of literature into a tool to analyze, question and challenge the realities that produce it.

Key words. Literary criticism, secular criticism, literature teaching and learning.

\footnotetext{
Bachiller en la enseñanza del inglés por la Universidad Nacional, Costa Rica. Magister en literatura inglesa por la Universidad de Costa Rica. Académico de la Sede Regional Chorotega de la Universidad Nacional, Costa Rica. Académico de la Universidad de Costa Rica, Sede de Guanacaste. En ambas instituciones se ha dedicado principalmente a la enseñanza de la literatura en lengua inglesa, cultura, expresión oral y composición escrita, entre otros. Entre las áreas de interés sobresalen los estudios poscoloniales, el análisis del discurso colonial, los estudios culturales y la didáctica de la literatura. Ha publicado artículos relacionados con dichos campos en revistas como Repertorio Americano y Letras, de la Universidad Nacional, Costa Rica; Intersedes, de la Universidad de Costa Rica, Itsmo, revista virtual de estudios literarios y culturales centroamericanos; así como ponencias en congresos internacionales y seminarios de literatura y educación tales como CILCA (Congreso Internacional de Literatura Centroamericana), CILAP (Congreso Internacional de Lingíistica Aplicada, de la Universidad Nacional, Costa Rica), Seminario Internacional de Educación de la Universidad Nacional, Costa Rica, Sede Chorotega.
} 
Nuestro hogar filológico es la tierra: no puede ser solo la nación.

Gianbattista Vico

\section{Introducción}

Una noción sumamente difundida en el currículum de la mayoría de los sistemas educativos, en todo nivel, ha dado por sentado el hecho de que la enseñanza de la literatura tiene como fines principales el aportar a la formación humanista de los estudiantes en su entorno, a la transmisión de valores morales y del bagaje de las literaturas nacionales, además de, claro está, su aprovechamiento estético como arte. Este enfoque tiende a escoger obras y autores que ayudan a cumplir dichos fines, mientras que la metodología aplicada a su análisis en el aula tiende a resaltar aquellas características de los textos que estén en comunión con los objetivos del sistema ideológico imperante.

Con esta concepción, y desde el surgimiento del concepto de literatura como una forma de sustentar una noción de identidad e ideología nacional, su enseñanza y divulgación han servido para reafirmar ideas como valores nacionales, morales, sociales, religiosos y de identidad y cohesión cultural. Es así como, según apunta Alfred Guerin (1999), surgen enfoques de análisis literario como el histórico-biográfico, en el que la literatura se percibe como un lente para mirar la constitución social de la época en que es producida; es decir, un reflejo de la vida y la época del autor o la vida y la época de los personajes de determinada obra; o el moral-filosófico, basado en las ideas de filósofos griegos y latinos como Platón u Horacio que enfatizaban el concepto de literatura como vehículo de transmisión de valores morales.

Por otra parte, a partir de principios del siglo XX, la literatura pasa a ser percibida como un discurso aparte que, irónicamente, auque transmite valores e identidades, pasa a ser visto como un tipo de discurso distanciado del lenguaje referencial de la vida cotidiana. Es en ese momento donde escuelas de análisis literario, a la postre sumamente influyentes, como el formalismo ruso o el formalismo norteamericano, perciben la literatura como un arte completo en sí mismo, con sus propios parámetros, sus propias reglas regentes y con su propia distancia de la realidad cotidiana. Román Jacobson, el teórico formalista ruso, apunta que la literatura es una forma de violencia organizada contra el habla ordinaria, es decir, un fenómeno que transforma e intensifica el lenguaje ordinario y de una manera sistemática se aleja de este (Eagleton, 1993); así mismo, para el formalista estadounidense Ranson (1979), un poema es una entidad completa en sí misma, cuyo análisis e interpretación no requieren ni dependen de factores externos. El significado total de la obra se encuentra analizando sus componentes, está en el poema en sí; por lo tanto, todo factor externo se descarta en su interpretación.

Estas escuelas favorecieron el énfasis en el análisis literario en elementos como sonido, imágenes, ritmo, sintaxis, métrica, rima y técnicas narrativas, entre otros. La difusión de estas escuelas, aunado al anteriormente mencionado concepto de literatura como instrumento para la contribución a la observancia de valores individuales y colectivos, contribuyó enormemente al distanciamiento entre su enseñanza y las realidades sociales que la producían. De este modo, casi toda la literatura que no aportara al esquema ideológico y a los valores de los grupos dominantes quedaba totalmente desterrada de las aulas, y en los casos excepcionales en que era incluida, su análisis se enfocaba en aspectos que no atentaran contra dicho esquema ideológico.

Sin dejar de reconocer algunas de las ventajas que aportan tanto las definiciones de literatura tradicionales como los métodos de su enseñanza, este artículo tratará de enfatizar el hecho de que, 
en todos los niveles, la didáctica de la literatura debe romper las barreras formalistas imperantes y se debe conectar a las realidades mundanas exteriores a las aulas, a las experiencias humanas $\mathrm{y}$, muy importante, a la relación que tiene la literatura con las instituciones de poder, tanto como abono a este o como elemento subversivo. Es mediante la aplicación del concepto de crítica secular a la enseñanza de la literatura que es posible tender puentes que logren acabar con tales barreras y se pueda difundir un concepto de literatura que vaya más allá de las definiciones tradicionales anteriormente anotadas.

\section{Crítica secular: un puente entre las letras y las experiencias humanas}

En su libro El mundo, el texto y el crítico, el pensador palestino Said (1983) afirma que los textos literarios son “(...) mundanos, y hasta cierto punto, son eventos, parte del conglomerado social, de la convivencia humana, y del curso de momentos históricos en los que se localizan e interpretan" (p. 222). Los textos, afirma Said, son posibles y son distribuidos entre el público gracias a "(...) las realidades de poder y autoridad, además de la resistencia de hombres, mujeres y movimientos sociales a las distintas instituciones, autoridades y ortodoxias" (p. 223). Son estas realidades las que, según Said, deberían considerar los lectores para crear una conciencia crítica distinta a la tradicional en torno a la literatura.

Para Said, el término conciencia crítica, que toma del pensador marxista Antonio Gramsci, implica, como apunta Bayoumi y Rubin (2000), el no ignorar o el no fingir ignorar el hecho de que la literatura está inevitablemente ligada a las realidades sociales y a las experiencias humanas, además de a las instituciones de poder. A partir del cultivo de la conciencia crítica en el lector, el análisis literario se puede convertir en una herramienta para cuestionar el estatus quo social y las castas intelectuales que perciben y difunden la literatura como simple disfrute estético o, en muchos casos, la utilizan para reforzar prácticas que fomentan el etnocentrismo, el nacionalismo exacerbado y el estancamiento generalizado de la distribución del poder.

A pesar de que podría sonar un tanto obvio, la sugerencia de Said de que la literatura y las experiencias humanas van inherentemente ligadas, ya muchos podrían afirmar que es de las experiencias humanas, canalizadas por escritores, de donde surge la literatura. La realidad crítica y didáctica es que este factor es ampliamente obviado en la enseñanza y en la crítica literaria, y cuando supuestamente no lo es, es usado para reforzar ciertos valores y discursos esnobistas e imaginarios, a costa de alteridades relegadas a un segundo plano por no concordar con los discursos de poder.

Es ahí donde es importante rescatar el término secular que, en la visión de Said, no debe implicar un simple modo de desprestigiar o despotricar contra organizaciones religiosas, como el término podría sugerir. Más bien, el uso del término para Said implica el tener cierto recelo o incredulidad ante parámetros usados por las distintas sociedades para definirse a sí mismas, definir sus conceptos de nación, civilización, raza, identidades sociales, jerarquías, tradición, religión, lo bueno, lo malo, lo aceptable, lo marginal.

Como en la mayoría de los casos sucede, en el imaginario colectivo se da por sentado que tales definiciones son inamovibles e inmutables y siempre han estado presentes y nunca han cambiado; cuando, todo lo contrario, más bien obedecen leyes perfectamente trazables y analizables y, en la gran mayoría de los casos, funcionan como elementos de dominio y poder. Como el mismo Said (1978) apunta, estas clasificaciones: 
(...) no son un acceso momentáneo de conocimiento objetivo, sino más bien un enjambre de estructuras heredadas del pasado, secularizadas y reformadas por disciplinas como la filología, que a su vez fueron sustitutas modernizadas y laicizadas de la visión de mundo del cristianismo. (p. 113)

Entonces, para usar las palabras del crítico Mufti (2004), la crítica secular “(...) lucha contra todas las imposiciones de modelos de nación o civilización por encima de la vida social y cultural, lucha contra todas las afirmaciones autoritarias y absolutistas que definen la membresía a una comunidad nacional (...)" (p. 3). Es decir, no se trata necesariamente de una lucha contra creencias absolutistas religiosas, sino también contra creencias absolutistas seculares, que en muchas ocasiones, y disfrazadas bajo el manto de lo secular, lo científico y lo objetivo son tan dogmáticas como las creencias religiosas.

La crítica secular es, entonces, un intento de desmantelar, como apunta Gunn (2004) "(...) todo reduccionismo, esencialismo, totalitarismo, y absolutismo que no son más que opios de la intelectualidad indolente y que a menudo conducen a la opresión mental" (p. 21). Este modo de pensamiento corresponde, en parte, a una condensación de pensadores tales como el filósofo francés Michel Foucault, quien sostiene que el conocimiento, la verdad y el poder son producto de presiones discursivas, institucionales y sociales; el pensador marxista italiano Antonio Gramsci, quien señala la contribución del intelectual orgánico a la institucionalización y legitimación del poder; el filólogo alemán Erich Auerbach con su secularización y pluralización de la historia de las identidades culturales europeas en su monumental obra Mimesis; y el pensador renacentista Gianbattista Vico, quien, de un modo innovador, apunta que conceptos como el de realidad o verdad se forman y verifican a través de la creación y la invención, y no a través de la observación.

Al condensar y ampliar con sus propias nociones las ideas de estos influyentes pensadores, Said nos invita, ya sea como críticos, lectores o estudiantes, a utilizar la literatura para analizar cómo se han creado, legitimado y estandarizado conceptos como los que apunta Gunn (2004): el oriente, lo femenino, la historia, el terrorismo, el occidente, el tercer mundo, el logocentrismo, el comunismo, Dios, la democracia, el imperialismo, y el modo en el que estos conceptos se han convertido en abstracciones difusas, cuasi sagradas y poco cuestionadas. A través del uso de la literatura para descubrir cómo tales conceptos son elaborados y legitimados, o bien cuestionados, es que podemos cumplir con ese objetivo primordial de realmente ligar la literatura, desde las aulas, al mundo fuera de estas.

\section{El modo de unir la literatura y las experiencias humanas a través de su enseñanza con los principios de la crítica secular}

Todo indica, ahora que se ha esbozado muy brevemente lo que se entiende por crítica secular, que es momento de señalar el modo de ser empleada a la hora de analizar obras literarias. Se pueden identificar obras literarias que promueven y ayudan a formar y mantener los discursos de poder, opresión y autoritarismo; también existen las que los desafían y los desmienten. También hay obras que ayudan a construir y diseminar conceptos como nación, patria y sociedad, y otras que los deconstruyen. La metodología de la crítica secular en el aula se debe basar en el modo de leer una obra, y de ahí en adelante se puede orquestar todo un giro en cuanto al modo de entender y disfrutar la literatura. 
En sus dos obras más influyentes, Orientalism [Orientalismo] (1978) y Cultura e imperialismo (1992), Said revoluciona el modo de ver los tres conceptos que constituyen los títulos de ambas obras. En el caso del orientalismo europeo de los siglos XVIII y XIX, Said sostiene que todas las ramas del saber involucradas en la exploración del Medio Oriente durante ese periodo contribuyeron enormemente, a través de su interpretación, a legitimar y justificar el expansionismo imperialista europeo sobre esas regiones, empezando con la invasión napoleónica a Egipto en 1798. En cuanto al segundo libro, Said establece una conexión muy interesante entre el imperialismo y la cultura. Afirma que el imperialismo no debe ser entendido solamente en términos hegemónicos, militares, políticos o económicos, sino también en términos culturales e intelectuales, que la mayoría de las veces, y de un modo silencioso, lo fomentan y lo legitiman.

Partiendo de estas premisas, podemos citar dos ejemplos de textos literarios, el primero ampliamente reconocido en el ámbito universal y el segundo un referente importantísimo del canon nacional: La tempestad, de Shakespeare (1976) y El sitio de las abras; de Dobles (1996), y como, ambos textos, vistos desde una perspectiva secular, pueden revelar nuevas interpretaciones que los ligan a la realidad cotidiana más allá de lo que la rigurosidad del formalismo permite.

Intentar ligar La tempestad con discursos de poder de nuestra realidad contemporánea -especialmente nuestra realidad como sujetos poscoloniales- con un pasado de opresión imperialista con vestigios que aún son palpables, no es tan descabellado como parece. En la obra, Próspero, el depuesto duque de Milán, es exiliado en una isla con su hija Miranda. Los habitantes nativos de la isla son Ariel, un espíritu etéreo que ha estado prisionero dentro del tronco de un árbol por doce años; Sycorax, una malvada bruja que, por los antecedentes previos a la obra sabemos que hizo prisionero a Ariel y que al momento de iniciar los eventos en que participan Próspero y Miranda ya ha muerto sin liberar a su cautivo; y finalmente el deforme y monstruoso Calibán, hijo de la bruja y de carácter débil y malévolo.

Próspero, quien además de duque es un poderoso hechicero, por medio de un acto de magia libera a Ariel e inmediatamente lo hace su sirviente. En cuanto a Calibán, quien intenta violar a Miranda, también es convertido en esclavo y obligado a cumplir todo tipo de tareas denigrantes después que la deforme criatura le ha mostrado a Próspero los secretos de la isla. De este modo, desde el principio, en la obra se establecen relaciones de poder entre Próspero y los nativos de la isla muy similares a las relaciones de poder que existieron entre los conquistadores y colonizadores europeos en el continente americano en la época contemporánea a la que Shakespeare escribió la obra, aproximadamente en 1610.

Podemos leer y enseñar La tempestad como una brillante instancia de teatro renacentista isabelino o como una ingeniosa comedia. Podemos aplicar a su estudio conceptos aristotélicos contemporáneos de análisis de la comedia teatral, como la suspensión de las leyes naturales, el orden social versus el orden individual, la premisa cómica, el humor verbal o las circunstancias previas, entre muchos otros factores típicamente tomados en cuenta en un clase de análisis de drama.

Sin embargo, también podemos leer esta obra entre líneas y ver cómo se constituye en uno de los primeros textos literarios que, de una manera u otra, dan por un hecho tan cotidiano como el aire que respiramos fenómenos como la colonización, la conquista de territorios de ultramar, la reducción a la servidumbre por derecho prácticamente divino e incuestionable a los habitantes de esas tierras; el percibir todo lo extraño como lo otro, lo ajeno, lo ambivalente, lo que se tiene que estudiar, conocer, dominar y someter, porque al ser tan distinto representa una amenaza, tal y como sucede con el deforme Calibán. Se puede comparar la ideología de conquista y sometimiento del otro -Calibán y Ariel-, que aparece en la pieza teatral, con el expansionismo británico en territorios de ultramar, que comenzaba a germinar en el momento cuamdo Shakespeare escribió La tempestad. 
Se puede estudiar el tipo de negociación entre colono - Próspero- y nativos -Ariel y Calibáncomo modelo de lo que serían las relaciones de poder entre conquistadores europeos y nativos de otros continentes durante los siguientes 350 años y lo que aún, en cierto modo, siguen siendo hoy en día. Se puede también explorar la filtración del epistema ideológico imperante en la época, en una obra que en apariencia no tiene nada que ver con la conquista y el colonialismo, y cómo Shakespeare, muy probablemente sin saberlo y sin importarle mucho el asunto, es partícipe activo de tales empresas, no sólo cuando escribió La Tempestad, sino también durante los siguientes 400 años, cuando personas de cuatro siglos distintos la leyeron o la vieron en las tablas sin pensar que de una manera u otra daba por un hecho incuestionable el dominio europeo sobre el resto del mundo y el derecho a dominarlo a través del distanciamiento entre Calibán, a través de sus características físicas y psicológicas, y Próspero y los demás personajes europeos, lo que justifica su sometimiento, del mismo modo que la ausencia de empatía sirvió para exterminar o someter naciones enteras durante cientos de años.

Al leer La tempestad de esta manera, se está conectando la obra con instituciones en apariencia ajenas a esta, aunque cuando estudiadas más a fondo se encuentran muy ligadas a su construcción, a su distribución y al modo de su estudio y enseñanza. Es de este modo que se tiende el puente entre una obra como La tempestad y nuestro pasado y presente, durante y después de cuatrocientos años, nuestra historia colonial y nuestro presente poscolonial y todo lo que ambos términos implican. Solamente una lectura que vaya más allá de una típica visión aristotélica de la obra nos permite ver esto y cuestionar cómo hemos estado leyendo y enseñando La tempestad a nuestros alumnos y cómo hemos desaprovechado todas estas posibilidades, si nuestra intención ha sido la de generar cambio y la de cuestionar el estatus quo de cómo hemos sido percibidos por la literatura más canónica que existe, y cómo nosotros mismos nos hemos percibido por medio de nuestras propias lecturas e interpretaciones de la misma, o más bien por lecturas e interpretaciones impuestas por otros.

En el caso de El sitio de las abras, de Fabián Dobles, tenemos a Espíritu Santo Vega y su familia, quienes emigran de Santa Bárbara de Heredia al litoral caribeño a colonizar y fundar nuevas tierras, derribando agreste selva virgen y luchando contra los elementos de la naturaleza y contra el poder rapaz de Ambrosio Castro, el terrateniente que intenta, por todos los medios, arrebatarles las tierras que tanto les ha costado domar y hacer productivas. Después de incontables luchas de Vega y los demás colonos que emigran de Heredia y Cartago, estos caen ante la maldad de Castro y sus ambiciones latifundistas. Los descendientes de los primeros sucumben ante la ambición del segundo y sus descendientes, son víctimas de explotación y son relegados a la servidumbre, sin más tierra que la que permanece en sus memorias, por la que tanto lucharon sus antepasados. Su intento de reproducir las bondades ideales del Valle Central en el litoral caribeño fracasa ante las injusticias de la opresión y la rapacidad del latifundismo.

Podemos leer esta novela como un producto del realismo social característico de la Generación del 40, de escritores como Dobles, Carlos Luis Fallas, Adolfo Herrera García o Joaquín Gutiérrez. Si nuestra lectura y enseñanza de dicha obra es como instancia de realismo social, podemos hablar de lucha de clases, de la explotación del hombre por el hombre, de los efectos del gran capital en el pequeño campesino. Desde el contexto socio histórico podemos agrupar El sitio de las abras dentro de la corriente literaria comprometida con causas socialistas y con un fuerte arraigo marxista, muy característico de la Generación del 40. También podemos hablar del legado literario de dicha generación en las generaciones siguientes de escritores e intelectuales costarricenses o de la literatura de colonización y exploración de nuevas zonas geográficas de nuestro país aparte del Valle Central. 
Estas interpretaciones pueden sonar bastante progresistas a algunos. Podríamos pensar que son una manera de ligar la literatura con la denuncia de las instituciones de poder que explotan a distintos grupos menos privilegiados. Sin embargo, también podemos estudiar al libro de Dobles como agente de instituciones de poder y como justificador de ciertas actitudes etnocentristas y excluyentes de ciertos sectores intelectuales de este país y de cómo sus actitudes han influido enormemente en la manera de percibirnos a nosotros mismos como habitantes de este país y a nuestro país como nación. Se puede estudiar y enseñar cómo la novela imagina y crea una Costa Rica que obedece reglas similares a las que, por ejemplo, rigen, la narrativa colonial y de viajes europea, principalmente la de los siglos XVIII y XIX y que de muchas maneras, como muchos teóricos han demostrado, contribuyó a justificar el colonialismo, el intervensionismo militar, el expansionismo imperialista, $\mathrm{y}$ el establecimiento de relaciones desiguales de poder entre colonos y nativos.

Se puede estudiar cómo el texto de Dobles es parte de la invención de una Costa Rica en la que lo único que realmente constituye la identidad imaginaria de lo que es el ser costarricense es lo que proviene del Valle Central, lo que proviene de sus habitantes labriegos y sencillos, imaginariamente blancos y pacíficos, su clima templado y benévolo. Todo lo opuesto a estas características constituyen al otro: los indígenas, los inmigrantes centroamericanos, la barbarie que ambos grupos representan en la novela, la inclemencia del agreste paisaje virgen que los colonos tienen que enfrentar opuesto el clima benévolo de Heredia o Cartago, la degeneración causada por las condiciones infrahumanas que acompañan la construcción del ferrocarril al Atlántico y el establecimiento de la United Fruit Company en el Caribe costarricense.

Es posible explorar cómo esta confrontación de características del Valle Central versus el resto del país reafirma presunciones etnocéntricas y racistas de una nación supuestamente blanca, civilizada, culta y pacífica y cuyo epicentro y fundación se localiza en el Valle Central, y cómo todo lo que no concuerde con estas características no es considerado verdaderamente costarricense. Desde esta perspectiva es posible ver el modo en el que El sitio de las abras más bien refuerza algunas de las situaciones que a primera vista intenta denunciar. Es posible ver cómo en su delineación y definición de nación, la novela de Dobles excluye de manera arbitraria a importantes sectores de la población y la geografía nacional, y lo más importante, cómo esta invención imaginaria de la Costa Rica actual, que no solo aparece en la novela de Dobles sino en muchos otras producciones de sus contemporáneos, se ha convertido en una definición de país casi absolutista y que no pocas veces ha arremetido fuertemente contra discursos emergentes que la confrontan.

Esta es la manera de realmente ligar una novela como El sitio de las abras a nuestra realidad, y no como comúnmente se ha relacionado, a la realidad de personas que enfrentaron las adversidades de los personajes de la obra hace ya mucho tiempo, ajenas a nosotros mismos y a nuestros tiempos. La definición de Costa Rica en la obra de Dobles aún se asienta fuertemente en nuestro imaginario y aún influye fuertemente en el modo de vernos a nosotros mismos y en el modo de ver, y en muchas ocasiones, discriminar o ignorar a quienes no son ni actúan como el sujeto imaginario que se llama a si mismo costarricense, aunque también sean parte de este país. En la mayoría de los casos, estas discriminaciones se dan por el solo hecho de no concordar con las características, puramente imaginarias, de lo que constituye un verdadero costarricense, como Espíritu Santo Vega.

\section{Conclusiones}

No es la intención de un artículo de esta extensión ilustrar, con ejemplos de actividades en el aula, cómo impartir una clase de literatura con base en la crítica secular. Ejemplos con ejercicios 
de análisis y discusión, y con estrategias de evaluación sería ciertamente material para un artículo aparte, y sería un artículo de por sí extenso si se quieren incluir todos los niveles de enseñanza. La idea que ha tratado de desarrollar este trabajo es mostrar el potencial que tiene la crítica secular, como modo de lectura, en la elaboración de metodologías que aborden el estudio literario como algo más que un ejercicio formalista. El principal ingrediente de la metodología misma es el cambio en el modo de leer. Este cambio debe llevarnos a una deconstrucción de la enseñanza tradicional a través de la conexión que debe existir entre literatura y mundo, entre intelectualidad y poder, entre cuestionamiento y cambio.

Esta innovación en el modo de leer debe estar en comunión con la manera de ver la educación como una herramienta de crecimiento y superación, no como un vehículo de adoctrinamiento o de simple aprendizaje de normas y oficios para convivir en una sociedad. El desarrollo de la conciencia crítica es sumamente importante para que la educación pueda cumplir esa función, y no podemos tener sociedades más justas y solidarias si no cuestionamos primero el status quo de estas.

En el caso concreto de las obras usadas como ejemplos en este artículo, el análisis secular de El sitio de las abras en un aula de secundaria o universitaria puede contribuir a la discusión acerca de la necesidad de una definición de nación más inclusiva, o a ver cómo conceptos como patria o país son en realidad ideas subjetivas cuya formación y difusión obedecen a intereses específicos, no imposibles de trazar y deconstruir. La Tempestad puede convertirse en una ventana que muestre cómo la visión de mundo que ha imperado en los últimos siglos también tiene un origen y una razón de ser regida por ciertos principios para nada incuestionables y que son posibles de cambiar.

Se podrían trabajar muchas obras en distintos niveles de enseñanza, pero la clave para su discusión y análisis serían las mismas: la literatura es mundana y está estrechamente ligada a la autoridad y al poder, tanto como advocada a estos o como oponente, pero la relación existe. El ejercicio es posible realizarlo con obras que van desde canciones de cuna o cuentos de hadas hasta producciones más elaboradas y ambiciosas como las usadas de ejemplo en este artículo. Tenemos que tener muy claro que el enseñar literatura sin ligarla a las realidades que la producen y la difunden $-\mathrm{y}$ estas realidades en la mayoría de los casos se sitúan fuera de las aula- es coartar los alcances de la gran mayoría de los textos literarios.

Si queremos contribuir a la formación de seres humanos capaces, no solo de entenderse a sí mismos, sino también de transformar su entorno en sociedades más justas y equitativas, no podemos ignorar que la literatura y su enseñanza pueden ser una gran herramienta para el cambio. Independientemente del nivel que estemos enseñando, de la literatura que estemos enseñando, de los ejes transversales que rijan nuestro sistema educativo o si podemos o no escoger nosotros mismos las obras que vamos a enseñar, la efectividad de la crítica secular y su uso en aras de la construcción de una conciencia crítica no dependen tanto de lo que se lea, sino de cómo se lea y cómo se enseñe. La premisa debe ser, como se apuntó anteriormente, el siempre tener cierto recelo o incredulidad ante los parámetros que usamos para definirnos a nosotros mismos, nuestra nación, nuestra sociedad, nuestras ideas del yo y del otro, de raza, civilización, y tantos otros conceptos que a menudo damos por sentados como inamovibles y que no son más que producto de luchas discursivas tan subjetivas, imaginarias y trazables como cualquier otro elemento de nuestra cotidianeidad. 


\section{Referencias bibliográficas}

Bayoumi, M. y Rubin, A. (2000). The Edward Said Reader. Nueva York: Vintage Books.

Dobles, F. (1996). El sitio de las abras. San José: Editorial Costa Rica.

Eagleton, T. (1993). Literary Theory: An Introduction. Nueva York: Vintage Books.

Guerin, A. (1999). A Handbook of Critical Approaches to Literature. Nueva York: Oxford University Press.

Gunn, G. (2004). On Edward Said. Scholarship Repository, 18, 21-34. Recuperado de escholarship. org/uc/item/6sj5q7nq

Mufti, A. (2004). Critical Secularism: A Reintroduction for Perilous Times. Boundary 31(2), 5-11.

Ranson, J. (1979). The New Criticism. New York: Greenwood Press.

Said. E. (1978). Orientalism. Nueva York: Vintage Books.

Said, E. (1983). The World, the Text, and the Critic. Nueva York: Vintage Books.

Said. E. (1992). Cultura e imperialismo. Barcelona: Editorial Anagrama.

Shakespeare, W. (1976). La Tempestad. (Obras completas). Londres: Penguin Books. 